\title{
.
}

Francesc Granell Trias*

\section{EL SISTEMA ECONÓMICO INTERNACIONAL EN 2021}

En 2021 la pandemia de la COVID-19, con sus sucesivas oleadas y cepas, ha creado un caos sobre las previsiones económicas. Hemos asistido a una nueva guerra fría entre Estados Unidos, China y Rusia, con nuevas fricciones comerciales, energéticas y cibernéticas. Ha habido poca fluidez y encarecimiento del transporte internacional, desabastecimientos de componentes y rotura de cadenas de valor y replanteamientos de deslocalización de producciones. Las políticas expansivas y los bajos tipos de interés han aumentado los niveles de deuda. Tensiones inflacionistas que no se conocían desde hace años han reaparecido. Los organismos mundiales, el G7 y el G20 no han encontrado soluciones para la gobernanza mundial y para alcanzar los objetivos de la Agenda 2030. Europa ha visto la culminación del Brexit y ha avanzado hacia una opción federal con el Next Generation EU para impulsar la economía y transformarla para competir con Estados Unidos y China, pese al Brexit y los populismos. España confía en salir de la crisis.

Palabras clave: COVID-19, migraciones, fletes, G20, criptomonedas, cambio climático, Next Generation EU, Brexit.

Clasificación JEL: E50, F02, F10, F13, F21, F45, G15, G28, H30, K33, L80, N17, O10.

\section{Introducción}

El 2021 ha sido, en muchos aspectos económicos, políticos, sociales y sanitarios, un año caótico en el que sucesivas oleadas de la pandemia de la COVID-19 han obligado a irse adaptando a la incertidumbre derivada de los problemas de cómo combatir las nuevas cepas

\footnotetext{
* Catedrático Emérito de Organización Económica Internacional de la Universidad de Barcelona y miembro de número de la Real Academia de Ciencias Económicas y Financieras del Instituto de España.

Este artículo forma parte de la serie que con el mismo título viene publicando el autor en el Boletín Económico de ICE, por estas fechas, anualmente, desde 1977.

Versión de diciembre de 2021.

DOI: https://doi.org/10.32796/bice.2022.3142.7344
}

de pandemia y de cómo resolver las discusiones sobre los instrumentos y políticas a utilizar para luchar eficazmente contra los contagios de la COVID-19, y se han sucedido los debates con los negacionistas sobre la eficacia de las vacunas, la saturación de los centros sanitarios para atender a los contagiados y el esfuerzo para crear rápidamente vacunas y hacerlas llegar a todos los países y no, simplemente, para vacunar a los que así lo acepten en países ricos capaces de comprar las vacunas.

Todas estas cuestiones e incógnitas sanitarias han influido grandemente sobre la macroeconomía, la microeconomía y las relaciones económicas internacionales que se han visto $D$ 
limitadas por los cierres de fronteras, aeropuertos y puertos para evitar contagios. Con este panorama sanitario y el frenazo económico derivado de la pandemia, muchas de las agendas de Gobiernos, empresas y organismos internacionales se han visto alteradas o han sido transformadas en fríos contactos telemáticos que no han propiciado mejorar el entendimiento entre los actores implicados en el sistema económico internacional.

En este contexto de crisis global, este artículo repasa lo que 2021 ha dado de sí, viendo las principales fricciones que se han producido en la esfera mundial, la rotura de las cadenas de suministro y otros problemas del comercio internacional, el rebrote de la inflación y las cuestiones monetarias y financieras, los avances y retrocesos hacia la consecución de los Objetivos de Desarrollo Sostenible y su Agenda 2030, y el creciente papel de las ciudades. El artículo se cierra con un análisis de lo que la Unión Europea ha avanzado en 2021 para hacer frente a los ajustes que se le han planteado y los problemas que se han recrudecido tras el Brexit, así como la necesidad de impulsar la economía para no perder posiciones en la economía mundial. También se hace una breve referencia a la economía española en este contexto global de crisis.

\section{El impacto de la COVID-19 y la nueva guerra fría Estados Unidos-China-Rusia}

En vísperas del año 2022, en que el Fondo Monetario Internacional (FMI) ha estimado que el PIB mundial alcanzará los 100 billones de dólares, el propio FMI ha calculado que la economía mundial habrá crecido en 2021 un 5,9\%, lo cual es poco si tenemos en cuenta que se ha partido de las bajas cifras de actividad de 2020. La realidad es que esta cifra y las del crecimiento de los principales países (India, 9,5\%; China, 8\%; Estados Unidos, 6\%; zona euro, $5 \%$; economías avanzadas, 5,2\%; países emergentes, $6,4 \%$ ) no pueden darse por definitivas, pues está todavía por ver el impacto que las variantes delta y ómicron de la pandemia van a llegar a tener si obligan al cierre de negocios y a un nuevo conjunto de medidas sanitarias restrictivas a la actividad económica como las que se registraron en 2020. Estas cifras son peores que las que se había pensado se producirían en el análisis efectuado por el FMI en julio de 2021.

El aumento de la demanda, contenida durante los cierres por la pandemia, los cuellos de botella y la insuficiencia de ciertos suministros y de energía que se están viendo a finales de 2021 , así como el aumento de los costes de transporte, han motivado un aumento de las tensiones inflacionistas como no se habían registrado en años, aunque el FMI cree que esta inflación será solo transitoria si la OPEP se aviene a suministrar más petróleo al mercado mundial y si las producciones de otras materias primas se regularizan y los suministros y el transporte vuelven a su normalidad prepandémica.

Hay que destacar, sobre todo, la sobredemanda de ciertas materias primas (litio, cobalto, grafito, cobre y níquel), demandadas para paneles solares, baterías y semiconductores, debido al gran aumento experimentado por sectores tales como los de teléfonos móviles, juguetes electrónicos y hasta componentes para la automoción.

Las marcas globales han seguido creciendo por encima del ritmo de avance de la economía global con un aumento muy significativo de Tesla (184\%). En el ranking global de marcas elaborado por Interbrand, la primera $\triangleright$ 
posición la ocupa Apple, con un valor de 408.251 millones de dólares, muy por encima de la segunda marca global que ocupa Amazon (249.000) y las siguientes, que son: Microsoft (210.000), Google (196.000), Samsung (74.000), Coca-Cola (57.000), Toyota (54.000), Mercedes Benz (50.000), McDonald's $(45,000)$, Disney (44.000), Nike (42.000), BMW (41.000), Louis Vuitton (36.000), Tesla (36.000) y Facebook (36.000). O sea, que las tecnológicas Apple, Amazon, Microsoft y Google suponen por sí solas más de un tercio del valor conjunto de las marcas globales, muy criticadas por sus prácticas monopolistas, fiscales y su vulneración de la privacidad y con multas recibidas de la UE y de los grandes países de la Organización para la Cooperación y el Desarrollo Económicos (OCDE).

En este análisis inicial sobre lo que ha dado de sí 2021 y, además, de las cuestiones comerciales, financieras y de los Objetivos de Desarrollo Sostenible que se glosarán más adelante, hay también que mencionar otras cuestiones significativas como las tensiones derivadas de los movimientos de emigrantes del tercer mundo tratando de introducirse en países desarrollados con mayores posibilidades para el futuro de sus hijos (piénsese que, según el Banco Mundial, el 10\% de la población mundial más rica acumula el $76 \%$ de la riqueza global) o para huir de conflictos políticos y hasta de guerras civiles en sus respectivos países de origen (Centroamérica, Siria, Afganistán, Sudán, etc.). Las fronteras de México-USA, Bielorrusia-Polonia, Turquía-Grecia, el Mediterráneo como paso entre Europa y África y Venezuela-Colombia han sido las más afectadas por ello este año.

De nuevo, la toma del poder por los talibanes en Afganistán, tras la retirada de las tropas norteamericanas en julio, no solo es una cuestión de migraciones y de terror de ciertas poblaciones a tener que vivir bajo la ley coránica, sino una fatal demostración de que Biden ha retirado a Estados Unidos de su tradicional función de custodio de los valores occidentales. Debemos recordar a este respecto que Joe Biden sustituyó a Trump el 20 de enero de 2021 tras un tumultuoso traspaso de poderes con asalto al Capitolio de los trumpistas el 6 de enero, lo cual ha debilitado, junto a las brutalidades raciales, la imagen de la democracia en dicho país norteamericano.

Biden, por otra parte, ha intentado dar marcha atrás a políticas que había implementado Donald Trump, ha marcado el retorno de Estados Unidos a organismos y acuerdos internacionales (Consejo de Derechos Humanos, Acuerdo de París sobre el clima, presencia en la UNESCO...) y ha puesto sobre la mesa medidas progresistas, como el aumento del impuesto de sociedades del 21 al $28 \%$, el aumento de impuestos a rentas superiores a los 400.000 dólares, lucha contra el racismo y las desigualdades sociales e inversiones en infraestructuras y subvenciones médicas.

Sin embargo, Biden no solo no ha corregido las tensiones entre Estados Unidos, la China de Xi Jinping y la Rusia de Putin, sino que las ha agravado en cuestiones tales como las apetencias de Pekín respecto a Taiwán, la presión sobre el mar de China Meridional y el problema de Ucrania, propiciando un acercamiento entre China y Rusia que solamente la Unión Europea trata de reencauzar por medio del diálogo diplomático en su papel de soft power.

El Partido Comunista de China ha cumplido cien años desde que se fundó en Shanghái en 1921, aunque la Republica Popular no se fundó hasta 1949, año en que Mao fue ayudado a $\triangleright$ 
ganar su guerra contra Chiang Kai-shek por Stalin, si bien la gran transformación económica de China solo se ha producido en los últimos años con Hu Jintao (2002-2012) y Xi Jinping (desde 2012). Un síntoma de la mayor fuerza china es que, en los últimos tiempos, no ha parado de aumentar el número de países que han dejado de mantener relaciones con Taiwán y reconocer solo a Pekín por las ayudas al desarrollo que les ofrece.

Tanto Estados Unidos como la UE aplican sanciones a dirigentes chinos y rusos por actividades que se considera atentan a los derechos humanos.

Aunque en forma mixta presencial y telemática, el Fórum de Davos celebró en febrero su 51. edición con el título de «El gran reinicio», poniendo sobre la mesa debates sobre la readaptación de las políticas fiscales y monetarias por los diferentes países, el trabajo a distancia, la mayor presencia del sector público en la economía, la posición dominante de las grandes empresas tecnológicas, el empleo en el futuro, las perspectivas del medioambiente y la aceleración de las desigualdades económicas y sociales consecuencia de la pandemia; la cual, por cierto, según la Organización Mundial de la Salud (OMS), puede convertirse en una enfermedad endémica.

A señalar aquí que la temática de las reuniones del G7 (47. 르 reunión en Carbis Bay, Cornualles, en junio, bajo presidencia de Johnson, y la 48. ${ }^{a}$ en Roma, bajo presidencia italiana de Mario Draghi) y del G20 (16. ${ }^{\text {a }}$ reunión en Roma, 30-31 octubre) han permitido focalizarse en la lucha contra el cambio climático, la prevención de pandemias, el proceso de vacunación y el impuesto mínimo a las grandes transnacionales. La reunión de Roma celebrada bajo el lema «People, Planet, Prosperity» pudo hacerse presencial aprovechando un periodo de calma pandémica, a diferencia de la Cumbre 15. de Riad (21-22 de noviembre de 2020), que tuvo que celebrarse de forma virtual.

Como cuestiones institucionales, el australiano Mathias Gorman ha sustituido al mexicano Ángel Gurría como secretario general de la OCDE el 1 de junio. Durante el mandato de Gurría, la OCDE ha entrado en nuevos temas y ha alcanzado la cifra de 38 Estados miembros. Por otra parte, el socialista portugués António Guterres, que sustituyó a Ban Ki-moon en el Secretariado General de las Naciones Unidas el 1 de enero de 2017, ha obtenido la reelección para el cargo para el quinquenio a partir de enero de 2022.

La XXVII Cumbre Iberoamericana, que no se pudo celebrar en 2020 por la pandemia, pudo tener lugar en formato semipresencial, presidida por Andorra, el 21 de abril, con presencia de dieciocho mandatarios de los veintidós Estados miembros, bajo el lema «Innovación para el Desarrollo Sostenible-Objetivo 2030», focalizándose en la recuperación pospandémica y las vacunas. El chileno Andrés Allamand fue elegido el 27 de noviembre secretario general de la Secretaría General Iberoamericana (SEGIB), organizadora de estas cumbres junto a las presidencias pro tempore. La XVIII Cumbre se celebrará en 2022 en la República Dominicana bajo el lema «Juntos hacia una Iberoamérica justa y sostenible».

La anterior secretaria del SEGIB, la costarricense Rebeca Grynspan, ha pasado a ser la secretaria general de la Conferencia de las $\mathrm{Na-}$ ciones Unidas sobre Comercio y Desarrollo (UNCTAD), desde el 13 de septiembre y por cuatro años, mientras que la nigeriana Ngozi Okonjo-Iweala ha pasado a ser la directora general de la Organización Mundial de Comercio (OMC) el 1 de marzo de 2021, una vez $\triangleright$ 
vencido el veto mantenido por Estados Unidos desde que Roberto Azevedo presentó su dimisión en mayo de 2020.

En cuanto a temas no estrictamente económicos, que han estado muy presentes en el debate internacional en 2021, hay que citar, además de la pandemia, el populismo, el indigenismo y el feminismo, que han avanzado fuertemente y que han dado lugar a situaciones tan curiosas como las críticas al colonialismo español tras la conquista y colonización de América protagonizadas por el nuevo presidente del Perú, Pedro Castillo, en presencia del rey de España - que había acudido a su toma de posesión-, así como al derribo de muchas estatuas de colonizadores españoles en Latinoamérica y Estados Unidos, sin que ni el presidente Biden y ni siquiera el Papa hayan adoptado posiciones contrarias a la leyenda negra antiespañola.

La pandemia, por su parte, registró, según la OMS, el máximo de fallecimientos el 9 de enero de 2021, cuando se alcanzó la cifra de 12.978 personas. Finalizamos 2021 con casi 300 millones de afectados y 5,5 millones de fallecidos, aunque estamos ante una nueva variante, la ómicron, que parece más contagiosa, pero con menos mortalidad que las anteriores cinco oleadas pandémicas, quizás por la masiva vacunación anticovid que se está produciendo en los países desarrollados con recursos. De hecho, si en el año 2020 se produjeron 1,9 millones de fallecidos, en 2021 se ha alcanzado la cifra de 3,5 millones, aunque esta no se sabe si refleja exactamente la situación, pues hay cierta confusión respecto a muertes por causas no estrictamente consideradas covid. Los países pobres, en todo este contexto, confían en recibir vacunas a través de la iniciativa COVAX con la que la OMS espera poder hacérselas llegar.

\section{El comercio internacional de bienes y servicios, fletes y contenedores}

El comercio internacional de bienes y servicios ha transitado el año 2021 con una serie de problemas a un nivel tal que mucha gente se pregunta si estos problemas no incidirán sobre la distribución mundial de plantas productivas que en los últimos tiempos habían basculado —quizás excesivamente- hacia países del Lejano Oriente, fundamentalmente hacia China, desde que esta entró en la OMC en diciembre de 2001.

El año empezó bien con el inicio del Acuerdo de Libre Comercio Continental Africano, incluyendo 55 Estados miembros con 1.300 millones de habitantes y amplias perspectivas de futuro -teniendo en cuenta el desarrollo demográfico que le espera a África-, pero los hechos han dado al traste con esta perspectiva positiva para las relaciones comerciales y turísticas mundiales.

La pandemia de la COVID-19 ha llevado a cerrar puertos y aeropuertos de todo el mundo, lo que, unido a los controles sanitarios impuestos y a la salida del Reino Unido del mercado interior único a causa del Brexit, ha generado un colapso muy serio en el tráfico mundial y, sobre todo, un enorme encarecimiento de los costes del transporte con especial incidencia en el movimiento de contenedores. Ello y la fatalidad del cierre del canal de Suez una semana en marzo, con un coste de 9.600 millones de dólares al día, según la Lloyd's List, por el atasco del enorme portacontenedores Ever Given, han desbaratado la cadena mundial de suministros hasta poner en peligro la globalización tal como ha funcionado hasta ahora. Este atasco ha impulsado, además, tensiones inflacionistas y desabastecimientos en fábricas, grandes almacenes y supermercados, $D$ 
especialmente intensos cuando el origen de los suministros era China, Corea del Sur o Taiwán. Esto ha sido tan grave que fábricas europeas de coches han tenido que suspender parcialmente su producción por falta de componentes y han tenido que plantearse reconsiderar la deslocalización en suministradores de países lejanos y el retorno de producciones a factorías europeas o norteamericanas, aunque sus costes de producción sean más elevados por los niveles salariales más altos de los países occidentales.

El año 2021 acaba sin que se haya superado del todo esta situación. Hay muchos barcos esperando cola en los grandes puertos mundiales (Los Ángeles, Hong Kong, Shanghái, Ningbo, etc.) y hasta un $10 \%$ de los contenedores mundiales están parados en los puertos a la espera de cargas de retorno o, simplemente, esperando a que las tripulaciones de los barcos salgan de la cuarentena a la que les han sometido los Gobiernos por miedo a la pandemia para no paralizar aún más los trabajos de estiba y desestiba. En este sentido, China ha establecido férreos controles portuarios por razones sanitarias, y hay que recordar que también se ha convertido en la gran factoría mundial absorbiendo materias primas fundamentalmente de África y América Latina.

La OMC ha podido, finalmente, dotarse de director general tras los vetos de Trump al respecto durante meses. Es así que la exministra de economía nigeriana Ngozi Okonjo-Iweala se ha hecho cargo de la dirección de la OMC el 1 de marzo de 2021, aunque con ello no se ha conseguido cerrar la 9. ${ }^{\text {a }}$ Ronda de negociaciones multilaterales y su Agenda de Doha; incluso, en 2021, no se ha podido reunir la

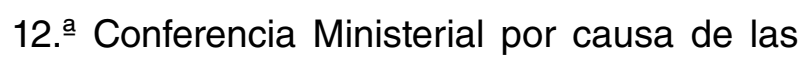
restricciones de movilidad por la pandemia. En 2021 se han producido ciertos avances en la liberalización del comercio de servicios desde la no demasiado exitosa 11. ${ }^{\text {a }}$ Ministerial celebrada en Buenos Aires en 2017 y la que debió celebrarse en Nursultán en 2020 o, al menos, en la sede ginebrina de la OMC a finales de 2021. Con todo, la OMC no ha conseguido renormalizar el funcionamiento del Órgano de Solución de Diferencias.

Temas enjundiosos como las sobrecargas tarifarias de Estados Unidos, la UE y otros países a las exportaciones chinas siguen sin resolverse (sobre todo, la afectación americana a determinadas exportaciones chinas pese al entendimiento de ambas partes respecto a reducción de emisiones y la buena predisposición mostrada por China al multar con 2.300 millones de dólares a Alibaba por abuso de posición dominante que afectaba también a las importaciones). En cambio, Estados Unidos y la UE han avanzado respecto a algunos de sus contenciosos comerciales, entre los cuales el más vistoso ha sido la transacción sobre las respectivas ayudas públicas a Boeing y Airbus, las trabas al comercio de aluminio y acero, y las sobrecargas a ciertos productos.

No se puede finalizar este epígrafe relativo al comercio de bienes y servicios sin hacer mención a la brutal caída del turismo internacional por las barreras anticovid decretadas por muchos Gobiernos. La UNCTAD ha estimado que el turismo internacional se contrajo un $74 \%$ en 2020 y que se habrá contraído aún un 2,7\% adicional en 2021. La UNCTAD estima, en cambio, que el comercio de bienes habrá crecido un $16 \%$ en 2021 , por lo que está ya un $3 \%$ por encima de su volumen prepandémico, no tanto por un aumento de volumen, sino como consecuencia del aumento de precios de materias primas y costes de transporte. La OMC, en cambio, nos dice que el comercio mundial cayó un 5,3\% en 2020 y que habrá $\triangleright$ 
crecido un $10,8 \%$ en 2021 , para tener un incremento del $4,7 \%$ en 2022 . Tamañas disparidades en los cálculos de ambos organismos nos hacen ver la confusión que está creando la COVID-19 en relación con la situación actual del comercio de bienes y servicios, debido a los aumentos de precios de la mayoría de commodities por los desabastecimientos, la expansión de la demanda recuperada después de que se contrajera por la pandemia y los bloqueos y medidas restrictivas dictadas por los Gobiernos al tráfico ante las sucesivas olas de pandemia con, además, impacto distinto en las diferentes áreas en función de los niveles de vacunación, los niveles de apertura de sus respectivas economías y los productos de exportación e importación de los países.

En relación con los regionalismos comerciales, Estados Unidos, México y Canadá han conseguido salvar el contencioso en el que habían entrado durante la Administración Trump con la reunión Biden-Trudeau-López Obrador (18 de noviembre), pero, en cambio, las desavenencias Brasil-Argentina están lastrando a tal punto a Mercosur que Argentina le ha dicho a Uruguay que, si no se siente cómodo por las políticas practicadas, abandone esta integración (59. ${ }^{\text {a }}$ Cumbre Presidencial virtual de 17 de diciembre). De hecho, Brasil, Paraguay y Uruguay desearían poder firmar acuerdos individuales con terceros países, a lo que se opone la Argentina del kirchnerista Fernández, por considerar que ello pondría en riesgo la continuidad de Mercosur.

Tanto el G7 como el G20, la OCDE y la UE (con su nueva estrategia comercial aprobada el 5 de febrero) siguen defendiendo el multilateralismo comercial, pero la realidad del multilateralismo es hoy bastante relativa, porque los acuerdos regionales siguen minando la cláusula de la nación más favorecida, por mucho que el artículo XXIV del GATT-OMC los hubiera aceptado como excepciones cuando el GATT se creó, como predecesor de la OMC, en un momento en el que el regionalismo comercial prácticamente no existía.

\section{Cuestiones monetarias y financieras, paraísos fiscales y las criptomonedas}

En 2021 se han cumplido cincuenta años desde que Nixon decretara el cese de la relación entre el dólar y el oro que se había establecido en Bretton Woods en 1944, y que, si hasta entonces había sido de 30 USD por onza troy, con el oro convertido en valor refugio, o, como diría Keynes, en reliquia bárbara, ahora alcanza en el mercado libre el precio de 1.800 dólares por onza. Aquella decisión está en la base de los déficits fiscal $(13,4 \%$ del PIB en 2021) y comercial (3,5\% del PIB en 2021) que Estados Unidos ha podido hacer, desde entonces, atendiendo solamente a sus conveniencias domésticas.

Con el Fondo Monetario, cuya directora gerente es la búlgara Kristalina Georgieva, ya no hay tipos de cambio fijos como antaño, pero los 190 países (el último ingresado fue Andorra en 2020) deben mantener la convertibilidad de sus monedas y a cambio de ello tienen la posibilidad de acceder a los recursos del FMI y a sus derechos especiales de giro (DEG). Un DEG es una especie de unidad de cuenta global y un activo de reserva que sus tenedores pueden cambiar por divisas de países superavitarios cuando lo necesiten.

EI FMI ha ampliado las capacidades financieras de sus Estados miembros con sus giros por valor de 117.000 millones a favor de 85 países desde que empezó la pandemia, y ha contribuido a aumentar el colchón de liquidez $\square$ 
internacional de sus Estados miembros a través de una nueva asignación, el 23 de agosto, de DEG, por valor de 650.000 millones, de los que 275.000 han ido a países emergentes, aunque, como los DEG se asignan en función de las cuotas de los Estados miembros, han sido los países con mayor cuota en la institución los que han recibido mayores asignaciones, lo cual no ha impedido que el FMI haya puesto a disposición de los veintinueve países más pobres hasta el mes de octubre de 2021 un total de 700 millones del Fondo Fiduciario para la Contención y el Alivio de Catástrofes del que dispone.

Desde inicios de la pandemia, el Grupo del Banco Mundial, presidido por el estadounidense David Malpass, ha comprometido créditos por un total de 125.000 millones de dólares para combatir los impactos sanitarios, económicos y sociales de la pandemia, protegiendo a los pobres, salvando empleos y generando una recuperación respetuosa con el clima, así como ayudando a financiar la adquisición de vacunas por los países más pobres con, aún, muy bajos niveles de vacunación.

FMl y Banco Mundial, en conjunción con expertos independientes y entidades académicas, han puesto en marcha (el 21 de junio) un Grupo Asesor de Alto Nivel sobre Recuperación y Crecimiento Sostenible e Inclusivo que debe marcar los caminos hacia el desarrollo verde, resiliente e inclusivo para el próximo decenio, tratando de guiar los pasos del G20 y de sus Estados miembros.

Por las acusaciones de corrupción respecto a la evaluación de algunos países en su informe Doing Business, precisamente en la etapa en que Giorgieva había sido directora general del Banco Mundial, esta institución ha dejado de publicar este informe anual orientativo de la marcha de la economía de cada Estado miembro y de su política respecto a las inversiones internacionales.

Durante 2021, muchos Gobiernos, el Banco Central Europeo (BCE) y muchos bancos centrales han desarrollado políticas expansivas y de relanzamiento para combatir la parálisis económica derivada de las medidas anticovid, siguiendo con ello las recomendaciones expansionistas de la OCDE, el G20 y el G7, contrarias a las políticas contractivas que se recomendaron en la crisis de 2008.

Los tipos de interés están a niveles prácticamente nulos en los principales países, aunque ha habido aumentos mínimos de los tipos en Chile y Corea del Sur en agosto; en Brasil, Colombia, México, Noruega, Chequia y Rusia en septiembre; en Polonia y Nueva Zelanda en octubre; y en Gran Bretaña y Noruega en diciembre. El aumento ha sido mayor en Turquía. El Bank of England ha llevado con ello su tipo de interés al 0,25\% y el noruego, al 0,50\%. Las políticas expansivas se han centrado mayormente en la compra de deuda pública y privada y en ayudas directas a familias y empresas. El FMI ha calculado que las ayudas estatales habían alcanzado los 16 billones de dólares hasta el tercer trimestre del año.

Con todo ello, los balances de los bancos centrales han crecido y los niveles de deuda han seguido el ritmo de ascenso que ya se había marcado en el ejercicio anterior. Según el Banco de Pagos Internacionales, el conjunto de deuda pública y privada habrá llegado en 2021 a los 300 billones de dólares, que equivalen a tres veces el PIB mundial. Los monetaristas creen que todo esto ha estimulado el rebrote inflacionista al que se está asistiendo en la última parte de 2021, si bien hay que decir que hay otros factores estructurales y desórdenes en el comercio y los suministros que están ayudando a las tensiones en los precios. 
Las monedas de los principales países no han sufrido desequilibrios importantes, aunque la libra esterlina, en razón de los desajustes económicos derivados del Brexit, ha experimentado un cierto retroceso, y la lira turca ha sufrido devaluaciones en un contexto de inflación del 30\% registrado este año. A final de año, el Gobierno Erdogán ha reducido el tipo de interés del $19 \%$ al $14 \%$ para tratar de reimpulsar la maltrecha economía turca.

En Estados Unidos, la inflación en noviembre se ha disparado hasta el 6,8\%, lo cual es el nivel más alto desde 1981, cosa que tiene muy preocupado al presidente Biden, que debe afrontar una elección de medio término en 2022 y en la que podría perder su mayoría en el Congreso.

Cuba puso en marcha el 1 de enero una reforma monetaria unificando los dos pesos que hasta ahora existían: uno para las transacciones domésticas (peso cubano o CUP) y el otro, el convertible, para las transacciones con el exterior (CUC) que empezó a circular en 1994, con una equivalencia de 1 USD = 24 CUP, cuando en la creación del sistema doble la relación con el dólar norteamericano era de 1 a 1. Los cubanos han dispuesto de seis meses para deshacerse de los CUC. Otra transformación monetaria a reseñar es la de Venezuela, en donde la hiperinflación y las sucesivas devaluaciones han hecho que el Gobierno de Maduro, el 2 de agosto, borre seis ceros del bolívar sin que ello sea propiamente una devaluación, sino una transformación del signo monetario nacional para disimular la monstruosa inflación registrada estos años en Venezuela.

Finalmente, cerramos este apartado monetario señalando que no se ha podido verificar la transformación del franco CFA, usado por quince excolonias francesas de África Occidental y Central, en el ECO tal como se había previsto, por la falta de acuerdo entre el Banco Central francés que soporta el franco CFA y las quince excolonias francesas que debían asumir la transformación.

En el plano tributario es destacable el hecho de que el G7, la OCDE, el G20 y los grandes países han aceptado la propuesta de establecer un tipo de imposición mínimo del 15\% para los beneficios de las grandes empresas que, hasta ahora, se aprovechaban de los paraísos fiscales y territorios fiscalmente agresivos y facilitadores de la elusión fiscal compitiendo en la atracción de inversiones extranjeras a base de una baja fiscalidad. Algunas de las grandes multinacionales tecnológicas se han defendido con uñas y dientes para impedir que esta medida fiscal tomara cuerpo.

En relación con las medidas monetarias y fiscales reactivadoras de las economías hay que citar que el mayor esfuerzo se ha hecho en Japón. En Europa, el BCE, desde marzo, ha decidido destinar 750.000 millones de euros al Programa temporal de compras de emergencia para la pandemia (PEPP, por sus siglas en inglés) como medida de política monetaria no convencional destinada a comprar deuda pública y privada de títulos, ya aprobado en el Programa de Compra de Activos (APP), ampliando, además, el programa con 500.000 euros más y prolongando su aplicación temporal hasta 2022. Tras ello, el balance del BCE alcanza los 7 billones de euros, equivalente al $68 \%$ del PIB de los veintisiete.

La economía estadounidense tiene la bolsa disparada (el índice Standard \& Poors está al nivel máximo de las últimas tres décadas), pues, con los poco remuneradores intereses de la deuda y de los depósitos bancarios, casi han desaparecido los activos sin riesgo y los ahorradores e inversores se han volcado hacia los valores bursátiles más atractivos por sus $\triangleright$ 
mejores perspectivas tecnológicas o las relacionadas con la salud o el lujo. Hasta finales de noviembre, dicha bolsa había recibido 1,1 trillones de dólares y sus niveles no parece que vayan a empeorar, ya que las perspectivas de inflación no van a condicionar las políticas monetarias dado que los altos niveles de deuda no van a hacer prudente subir los tipos de interés (salvo algún pequeño retoque en 2022), lo cual viene, además, avalado por el hecho de que la Reserva Federal y el Gobierno no van a desescalar más que muy moderadamente sus políticas ultraexpansivas, pues no se quiere que la desaceleración de la economía china afecte a las perspectivas de la economía norteamericana.

Además, y para acabarlo de situar, Estados Unidos está prácticamente en situación de pleno empleo por falta de mano de obra calificada para las nuevas profesiones pospandémicas, cosa que está a la base de la inflación disparada (el 6,8\% en noviembre) por la retroalimentación derivada de los aumentos salariales por el pleno empleo. Este ritmo de inflación no se registraba desde hace cuarenta años.

Las criptomonedas han seguido jugando un papel ambivalente en la esfera monetaria y financiera. Mientras en algunas redes sociales se invitaba a los ahorradores a comprarlas para enriquecerse, la especulación sobre algunas de ellas ha generado una inestabilidad que ha hecho que algunas autoridades monetarias desaconsejen su adquisición especulativa. Pese a ello, el sector de las criptomonedas se está mostrando muy atractivo para los jóvenes especializados en estas cuestiones, lo cual da lugar a que estos muestren menos interés por buscar empleo en otros sectores informáticos, teniendo en cuenta, además, la poca fiscalidad que recae sobre los beneficios derivados de las criptomonedas.

\section{Objetivos de Desarrollo Sostenible, cambio climático y ciudades}

Cuando las Naciones Unidas aprobaron los diecisiete Objetivos de Desarrollo Sostenible (ODS) en 2015, todo el mundo sabía que muchos de tales objetivos eran declaraciones de principios que no iban a poder alcanzarse plenamente, pero nadie podía imaginar que la inesperada pandemia de la COVID-19 (iniciada a finales de 2019 en Wuhan y extendida a todo el mundo) fuera a añadir nuevas sombras y dificultades para conseguir que los objetivos de la Agenda 2030 pudieran más o menos alcanzarse como inicialmente se había declarado.

Hay objetivos que son especialmente difíciles de alcanzar, como es el caso del 13. (acción por el clima), en el que en la 26. ${ }^{\text {a Reunión }}$ de la Conferencia de las Partes en la Convención Marco de las Naciones Unidas sobre el Cambio Climático (COP26), celebrada en Glasgow a mediados de noviembre, con representantes de 197 países y territorios, organizaciones internacionales y ONG, se ha constatado la enorme dificultad de poder avanzar hacia las metas establecidas en los Acuerdos de París en 2015 y en el que se proponía que el nivel de calentamiento climático no superara un aumento de $1,5 \stackrel{\circ}{\circ} \mathrm{C}$ a finales de siglo. Tampoco se ha conseguido avanzar en la movilización de 100.000 millones de dólares para la lucha contra el cambio climático, y los países con producción de petróleo y carbón se han opuesto a condicionar su desarrollo a su suspensión y a la reducción de emisiones respecto a las de 2010 en un $45 \%$ para 2030.

Algunas ONG medioambientalistas han dicho que la COP26 ha sido un puro blablablá, señalando los abusos en movilización de aviones privados contaminantes y de coches que han supuesto la movilización de líderes $\triangleright$ 
mundiales participantes en la reunión de Glasgow, al tiempo que el grupo de los pequeños países insulares en desarrollo, encabezados por Maldivas y Tuvalu, apuntaban al negro panorama que les espera por su poca esperanza a que se frene el aumento del nivel de océanos y mares, con la consiguiente pérdida de territorio y, sobre todo, de sus playas turísticas.

Hay meteorólogos que afirman que este retraso en la lucha contra la degradación medioambiental explica en parte la serie de catástrofes naturales que se han producido a lo largo del año y que van desde las sequías extremas hasta las inundaciones y otros fenómenos. Las compañías de seguros especializadas han calculado que de unos 8.000 millones de euros de indemnizaciones que se producían en la década de 1980 se ha pasado a 44.000 millones en 2021.

Con relación al ODS de lucha contra el hambre, la FAO sostiene que el aumento de los precios de los alimentos y la caída de algunas producciones en Estados Unidos, Brasil y Ucrania van a hacer más difícil su erradicación en los países pobres dependientes de la importación de alimentos. El índice de precios de la FAO se encuentra, a finales de 2021, en su nivel más alto de los diez últimos años, y existen muchas dudas sobre la continuidad del sistema alimentario tal como lo conocemos hoy, ya que emplea el $70 \%$ de los recursos de agua y el $48 \%$ de los recursos de la tierra a escala mundial, además de ser responsables del $34 \%$ de las emisiones de gases de efecto invernadero, considerando desde las emisiones derivadas del cambio de uso de la tierra (como las deforestaciones) y la producción agrícola hasta las fases del envasado y la gestión de residuos, así como los gases derivados de la ganadería.

Otro ODS de imposible consecución al nivel actual de la tecnología es el 7.ำ, referido a una energía accesible y no contaminante. Como se explicaba en The Economist del 16 de octubre, el intento de abandono del carbón, los combustibles fósiles y la energía atómica no se ve compensada por las energías eólicas, solares e hidráulicas limpias, y la tecnología del hidrógeno aún no está disponible, con lo que se va a asistir a un periodo de insuficiente oferta energética con el encarecimiento que ya se está viviendo en 2021. El precio del barril de petróleo tampoco ayuda, pues está por encima de los 80 dólares, como no sucedía desde 2014, debido a la fuerte recuperación de la demanda tras un periodo de pocas inversiones energéticas tradicionales por la escasez de demanda en el periodo de más estrictos confinamientos.

Cuando parecía que la amenaza de la covid se iba superando, la llegada de la variante ómicron (que ha vuelto a frenar la actividad económica) ha acabado de desorganizar el sistema energético. Al mismo tiempo, las fricciones políticas en Oriente Medio, la caída de producciones de algunos productores tradicionales, las sanciones a Rusia por la cuestión de Ucrania y el complejo porvenir del gaseoducto directo entre Rusia y Alemania (Nord Stream 2) -que evitaría la servidumbre del gaseoducto que transita hacia Europa Occidental por Ucrania y Bielorusia- por la amenaza de sanciones norteamericanas a las empresas que lo construyen, lo retrasan todo. Por otra parte, hay otro peligro político presente. El contencioso entre Argelia y Marruecos, que impide la utilización de uno de los gaseoductos que unían Argelia con España, ha obligado a confiar en los suministros por gas licuado, más costoso, y ha forzado a varios grandes países a movilizar, incluso, una parte de sus reservas estratégicas de crudo, mientras la OPEP se niega a aumentar la producción por miedo a que una nueva ola $\triangle$ 
pandémica vuelva a parar la demanda y se vaya a una nueva caída de precios.

La crisis derivada de la pandemia ha causado estragos en el mercado de trabajo y ha forzado a nuevas opciones como el teletrabajo o, incluso, a la aceptación cada vez más amplia de esquemas de renta básica universal para evitar que los altos niveles de desempleo desemboquen en situaciones de tensión social más elevadas haciendo imposible la consecución de varios ODS asociados al bienestar de la población y al empleo.

EI World Economic Forum de Davos está resaltando el creciente papel de la ciudad para mejorar la vida de sus ciudadanos y la lucha contra el cambio climático, ampliando sus zonas verdes, plantando árboles y limitando la polución por circulación de vehículos, así como atendiendo las necesidades de las poblaciones más vulnerables y creando áreas tecnológicas y de investigación. La lista del World Economic Forum incluye, como cinco ejemplos de iniciativas copiables por otras ciudades, a París, Bangkok, Nueva York, Nairobi y Barcelona. Esta lista ha sido discutida desde las redes sociales, que han mencionado otras ciudades con otros proyectos medioambientales dignos de mención como Ámsterdam, Madrid, Porto Alegre o Cardiff. Esta iniciativa del World Economic Forum pone de manifiesto el creciente papel de las ciudades en la gestión de la lucha medioambientalista y en conseguir clusters tecnológicos durante la pandemia.

La UNCTAD XV de Bridgetown, Barbados (celebrada telemáticamente del 3 al 7 de octubre), ha respondido al lema «Desde la desigualdad y la vulnerabilidad hacia la prosperidad para todos", y en ella se ha puesto de manifiesto que los mecanismos de lucha a favor de los ODS asociados a la lucha contra el subdesarrollo en todas sus manifestaciones
(Agenda del Desarrollo, hambre, pobreza, mortalidad infantil, mujeres o, incluso, justicia y gobernanza) están sufriendo unas modificaciones sustanciales. De hecho, se ha frenado el ritmo de reducción de la pobreza que se había puesto en evidencia antes de la crisis financiera de 2008 y la crisis pandémica de 2020-2021, lo cual se ha debido a los problemas presupuestarios de los países del Comité de Ayuda al Desarrollo de la OCDE, que no han sido compensados por el aumento de la acción china y los países ricos del Golfo en su ayuda al desarrollo ni, tampoco, por los flujos privados de inversión (ni, incluso, con las nuevas fórmulas de blending), y mucho menos por las remesas de emigrantes, aun a pesar de los movimientos de migrantes y refugiados registrados. Los grandes temas tratados en la UNCTAD XV por líderes mundiales, jefes de agencias e instituciones financieras globales, así como por grandes ONG y representaciones de la sociedad civil y de la juventud, han sido el desigual acceso a las vacunas, los problemas del comercio de bienes y servicios, la deuda, las nuevas tecnologías, la inteligencia artificial, la robótica, los drones y el cambio climático y sus implicaciones para los países pobres.

Con los compromisos asociados a los ODS, los propios países del Sur deben movilizar sus recursos internos para salir de la pobreza, actuación que antes no les exigía el sistema internacional.

Con manifestantes quemando el mobiliario urbano y registrándose, incluso, muertos por enfrentamientos con las Policías, habría que reconocer que los ODS que han avanzado menos son los que se refieren a un trabajo digno (ODS n.․ 8) y reducción de las desigualdades (ODS n. 10 ), mientras que el ODS n. 9 (industria e innovación) avanza por impulso de la revolución tecnológica que conlleva la $\triangleright$ 
cuarta revolución industrial que está acompañando a la pandemia y por la investigación emprendida por las multinacionales y por las empresas más innovadoras.

EI ODS que ha quedado más atrasado, a la vista del proteccionismo y los pocos avances en el sistema multilateral, es el $n . \stackrel{0}{17}$, que llama a la colaboración de todos para alcanzar los objetivos, pues, pese a la substitución de la Administración antiglobalista de Trump por la teóricamente más abierta de Biden, el multilateralismo sigue en muchos sentidos en crisis por la nueva «guerra fría» que se está produciendo entre Estados Unidos, China, Rusia y, en cierta manera, la Unión Europea.

\section{La Unión Europea, el Brexit y la zona euro}

Durante 2021, han ostentado la presidencia rotatoria del Consejo de Ministros de la UE Portugal en el primer semestre y Eslovenia en el segundo, pero el liderazgo de la acción europea ha estado en manos de la presidenta de la Comisión Europea, Ursula von der Leyen, que ha impulsado la integración europea hacia una vía federal, y el tándem francoalemán con Macron - tratando de posicionarse para ser reelegido en las elecciones presidenciales de 2022 - y Angela Merkel, que tras las elecciones del 26 de noviembre, a las que no se presentó tras dieciséis años de mandato, ha dejado la cancillería en manos del socialdemócrata Scholz (el 8 de diciembre) al frente de una coalición en la que figuran, además de los socialdemócratas, los liberales y los verdes (coalición llamada Semáforo). Scholz pasa a ser el cuarto canciller socialdemócrata alemán tras Willy Brandt, Helmut Schmidt y Gerhard Schroeder. El primer nombramiento del nuevo Gobierno, el
21 de diciembre, ha sido el de Joachim Nagel (hasta ahora subdirector en el Banco de Pagos Internacionales) como nuevo responsable del Bundesbank a partir del 1 de enero de 2022, en sustitución de Jens Weidman.

Al margen del desaire turco a la presidenta de la Comisión en la visita de la UE a Estambul al dejarla sin silla preferente (7 de abril), la presidenta de la Comisión Europea, Ursula von der Leyen, ha tenido un papel importante para hacer avanzar a la Comisión en diferentes aspectos de la vida comunitaria. El primero ha sido su capacidad de convicción a los Estados miembros para desbloquear (31 de mayo) el Marco Financiero Plurianual 2021-2027 con 2.018 billones de euros (cuyas primeras partidas son la cohesión y la resiliencia y los recursos naturales, que incluye la Política Agrícola Común, con un primer acuerdo sobre su reforma en junio de 2021). El medioambiente (Pacto Verde Europeo, presentado el 14 de julio tras haber sido anunciado por Von der Leyen en su primer discurso sobre el estado de la Unión), ocupa la tercera posición de gastos presupuestarios, proyectándose que se alcance el objetivo de la neutralidad climática para 2050. El 9 de marzo se presentó la Década Digital de Europa con el objetivo 2050, incluyendo principios y derechos digitales y empoderando a la ciudadanía al respecto. Para multiplicar las sinergias entre las industrias civil, de defensa y del espacio, el 22 de febrero, la Comisión presentó un programa que debe reforzar el nivel tecnológico europeo. La acción exterior (Europa Global) representa algo más del $5 \%$ de los gastos, a pesar de que, a diferencia de lo que había sucedido en el pasado con los convenios de Yaoundé, Lomé y Cotonou, el hasta ahora Fondo Europeo de Desarrollo (FED) ha pasado a integrarse en el Presupuesto General de la UE, dejando de ser el fondo que hasta ese momento $\triangleright$ 
se nutría de contribuciones directas de los Estados miembros de acuerdo con su respectivo peso, bien que modificado por otros parámetros y destinado a financiaciones para los países de África, Caribe y el Pacífico (ACP).

Con respecto al presupuesto hay que mencionar que se ha adicionado como nuevo recurso propio en el capítulo de ingresos el relativo a los residuos de envases de plástico no reciclable.

Junto a ello, es forzoso mencionar la aprobación del paquete de 723.800 millones de euros del Mecanismo de Recuperación y Resiliencia, que va a financiarse con la emisión, por la propia Comisión, de deuda a largo plazo, lo cual da a toda esta operación un tinte marcadamente federal europeo en donde la Comisión allega los recursos acudiendo a los mercados de capitales (la primera operación de 20.000 euros se realizó el 15 de junio, siendo sobredemandada hasta tal punto que, en 2021 , se han podido lanzar operaciones por 80.000 millones de euros). Por otra parte, la Comisión repartirá los fondos entre los Estados miembros que lo demanden en forma de subvenciones (338.000 millones) y préstamos (385.000 millones). Este plan, conocido como Next Generation EU, debe conseguir que Europa salga mejor de la crisis pandémica, impulsando que los Estados miembros presenten planes nacionales de recuperación y resiliencia en donde asuman los grandes objetivos que la Comisión estima permitirá que Europa alcance mejores niveles de competitividad en el mundo en aspectos tales como las energías alternativas, la banda ancha, la modernización digital, el reciclaje y el perfeccionamiento profesional, la lucha contra la degradación del medioambiente, las ciudades sostenibles, la renovación energética de edificios y otras. Cada uno de los planes nacionales de los veintisiete debe incluir un mínimo del 37\% para gastos e inversiones en el ámbito del clima y del $20 \%$ para impulsar la transición digital.

En relación con la lucha contra la pandemia, la Comisión está liderando la salida a nivel europeo centralizando la adquisición de vacunas para distribuirlas tanto a los Estados miembros como dedicando, incluso, una parte al programa COVAX para enviar vacunas al tercer mundo, y se han puesto en marcha iniciativas de investigación sobre las variantes de la COVID-19 y de realización de pruebas de detección. En mayo de 2021 se adaptó la legislación sobre protección civil para resistir mejor a los nuevos riesgos derivados de la pandemia y su evolución, y a las catástrofes. Al mismo tiempo, se ha conseguido poner en marcha el certificado covid de la UE (pasaporte), que, incluso, han adoptado países países europeos no miembros de la UE.

Aprovechando la capacidad de movilización mundial de la Comisión, y en colaboración con Italia, se organizó el 21 de mayo la primera Conferencia Internacional de la Salud, que ha abierto nuevas líneas de acción para ampliar actividades relacionadas con la crisis actual y posibles evoluciones sanitarias, con un firme rechazo a las limitaciones al comercio internacional de productos farmacéuticos e impulsos para hacer llegar vacunas, productos sanitarios y técnicas adecuadas a los países pobres, así como la potabilización del agua. La asistencia se ha previsto para 130 países.

En colaboración, en este caso, con la presidencia portuguesa del primer semestre del año, se celebró en Oporto una Cumbre Social (7 y 8 de mayo) para reforzar el pilar europeo de derechos sociales y una serie de objetivos a alcanzar para 2030, en donde los temas estrella fueron la formación y el aprendizaje permanentes, reducción del número de personas $\triangleright$ 
en riesgo de pobreza y exclusión social (especialmente los niños), la igualdad de género y personas (LGBTIQ+, gitanos, discapacitados...), así como la renta mínima, las prestaciones de desempleo, las pensiones en riesgo por las tendencias demográficas, el diálogo social y las acciones de apoyo temporal para atenuar los riesgos de desempleo en una emergencia (Programa Sure, adoptado el 21 de octubre de 2020), en donde Italia y España han sido mayores beneficiarios en 2021.

La Comisión ha introducido desde el 1 de enero el seguimiento sobre el Estado de derecho en la UE, con varios problemas planteados en relación con los sistemas judiciales en Hungría y Polonia.

El 2021 ha sido el año en que definitivamente la UE ha pasado de 28 a 27 miembros al culminar el proceso de abandono de la UE por Gran Bretaña, que se había iniciado con el referéndum del 23 de junio de 2016 convocado por Cameron y con la notificación de Theresa May, el 27 de mayo de 2017, a la UE del deseo británico de abandonar la Unión. Tras las negociaciones del Brexit, conducidas por parte europea por Michel Barnier, el Acuerdo sobre la retirada de Gran Bretaña de la UE y del Euratom entró en vigor el 1 de febrero de 2020 y, desde el 1 de enero de 2021 y hasta el 28 de febrero de 2021, se pasó por una situación transitoria final presidida por las actas de abandono y el Acuerdo de Comercio y Cooperación UE-Reino Unido, regulador de la relación entre ambas partes a partir del abandono de Gran Bretaña de la integración europea, formando mercados separados con los correspondientes controles aduaneros y sanitarios recíprocos.

A lo largo de 2021 la separación no ha resultado fácil, pues Gran Bretaña ha tenido que padecer una serie de problemas derivados de los arreglos referidos al comercio entre la
Irlanda del Norte británica y el resto de Irlanda miembro de la UE, el acuerdo de pesca entre ambas partes y las dificultades de tránsito en el Canal de la Mancha, así como el control de migrantes ilegales en el Canal, amén de los problemas de mano de obra que el Reino Unido ha venido padeciendo como consecuencia de no poder disponer sin trabas de nueva mano de obra de otros países europeos de la UE. La conclusión de todo ello es que el Reino Unido ha hecho un flaco negocio saliendo de la UE, como muestran las encuestas hoy claramente decantadas a decir que el Brexit no ha resultado positivo como los brexiters hicieron entender con mentiras a la población británica, cuando Cameron convocó el referéndum con el convencimiento de que el pueblo no votaría por el Brexit, sino por el Remain.

Para la UE-27 la retirada del Reino Unido significa la pérdida del país con mejor ejército, marina y potencia nuclear, de cara a que la UE pudiera dotarse de una acción exterior militar singularizada, dentro de la OTAN, y algo más en consonancia con su fuerza económica.

Con respecto a la zona euro, esta no ha sufrido variaciones importantes a lo largo de 2021. La Comisión ha hecho la vista gorda en relación con los países con déficit excesivo con el fin de no impedir que los países de la zona no pudieran llevar a cabo políticas expansivas. EI BCE, por su parte, ha continuado su programa de compra de activos públicos y privados ayudando, así, a los países que, en su lucha contra la pandemia, se han visto obligados a endeudarse muy por encima de los porcentajes admitidos por el Tratado de Maastricht.

A reseñar, finalmente, que la UE ha comenzado el 9 de mayo el proceso de la Conferencia sobre el Futuro de Europa, que debe culminar durante la presidencia rotatoria francesa del primer semestre de 2022. 


\section{España y el sistema económico internacional}

Según cálculos del Centro de Investigación Económica y Empresarial (CEBR) de Londres, España, que antes del pinchazo de la burbuja inmobiliaria en 2008 estaba en el puesto 9 del ranking mundial en $\mathrm{PIB}$, en los próximos años va a caer al puesto 15 con una tasa anual de crecimiento del 2,6\%. Los datos de 2021 corroboran que España es el país desarrollado que más está tardando en recuperar los niveles prepandémicos, si bien en la última parte de 2021 se ha asistido a una discusión sobre el ritmo de crecimiento de la economía española durante el año que podría alterar esta tendencia.

El Gobierno dio la cifra del $6,5 \%$ de crecimiento cuando se aprobaron los presupuestos para 2022, cifra considerada demasiado optimista por el FMI, la OCDE, el Banco de España y la propia Comisión Europea, que la han situado en el $4,8 \%$, aunque se produce la circunstancia de que los ingresos tributarios en los primeros tres trimestres de 2021 están creciendo a un ritmo superior al $13 \%$, lo cual parece indicar que los cálculos de evolución del PIB que efectúa el Instituto Nacional de Estadística (INE) infravaloran los avances en nuevos sectores de la economía o las compraventas de viviendas y vehículos de segunda mano, ya que no ha habido nuevas figuras tributarias suficientes que lo justifiquen, más allá de la introducción del impuesto sobre transacciones financieras de empresas con más de 1.000 millones de euros de capitalización bursátil (tasa Tobin), que se ha empezado a aplicar desde el 16 de enero, o la tasa Google sobre determinados negocios digitales, aunque ambos no han conseguido recaudar lo que había esperado el Ministerio de Hacienda, lo mismo que ha sucedido con algunos retoques en el proceso de liquidación de beneficios de ciertas empresas y tramos superiores de varios impuestos con progresividad.

El elevado déficit presupuestario derivado de las acciones anticovid (-11\%) y las necesidades de hacer frente a las medidas de salvación de empresas y familias afectadas por la COVID-19 ha hecho crecer el volumen de deuda pública en relación al PIB hasta el 119,5\%, cifra que se estima podrá rebajarse hasta el $115 \%$ en 2022 si la tasa de crecimiento del PIB es superior a la de 2021 y no se ve demasiado afectada por la nueva ola pandémica, que está obligando a adoptar nuevas restricciones sanitarias con incidencia en la marcha del turismo, la restauración, el ocio y el transporte, y si se consigue controlar el aumento de las inversiones necesarias para luchar contra el cambio climático.

A lo largo de 2021, Pedro Sánchez ha efectuado varios ajustes de gobierno, pero los más importantes, con respecto a las relaciones de España y el sistema económico internacional, han sido el acceso de Nadia Calviño a la vicepresidencia primera del Gobierno en julio de 2021, tras la decisión del anterior vicepresidente primero del Gobierno, Pablo Iglesias, de dejar el cargo para disputar a Isabel Díaz Ayuso la presidencia de la Comunidad de Madrid en la elección del 4 de mayo. Nadia Calviño había sido vicepresidenta tercera del Gobierno desde junio de 2018, cuando Sánchez sustituyó a Rajoy en la Moncloa, siendo, también, ministra de Asuntos Económicos y Transición Digital. El 10 de julio de 2021 se produjo, por otra parte, el relevo en el Ministerio de Asuntos Exteriores, Unión Europea y Cooperación, en el que Arancha González Laya fue sustituida por el diplomático y exembajador en París José Manuel Albares. 
La vicepresidenta Nadia Calviño, que en 2019 había accedido a la presidencia pro tempore de la Junta de Gobernadores del Banco Europeo de Reconstrucción y Desarrollo (BERD), ha sido elegida el 23 de diciembre de 2021 presidenta del Comité Monetario y Financiero del FMI — tras ser elegida candidata europea al cargo por los Ministros Europeos de Economía y Finanzas (ECOFIN)- Calviño simultaneará esta presidencia, desde enero de 2022, con sus responsabilidades en el Gobierno de España.

En 2021 España ha tenido que lidiar en el plano internacional con el conflicto derivado de la presencia, en razón de su estancia en una clínica de Logroño, del presidente de la República Saharaui y líder del Polisario Brahim Gali, lo cual creó una fuerte tensión con Marruecos, agravada por el veredicto del Tribunal de la UE que dictaminaba que los acuerdos pesqueros con la costa africana no pueden hacerse solo con Rabat y debe contarse con el Polisario (29 de septiembre).

A esto hay que añadir el desagradable incidente del rey Felipe VI en su visita al Perú en que recibió críticas a la presencia española en América, hace quinientos años, de forma descortés por parte del nuevo presidente del Perú, José Pedro Castillo, el día de su toma de posesión en Lima (25 de julio), circunstancia, por cierto, coincidente con una oleada de reivindicaciones indigenistas y antiesclavistas en todo el continente americano con derribo incluido de estatuas de descubridores, colonizadores, misioneros y hasta lideres sudistas de la guerra de Secesión norteamericana.

En el contexto de las negociaciones del Brexit, por las que el Reino Unido ha salido del Mercado Único Europeo, se ha producido un acuerdo interino sobre la gestión de la frontera entre Gibraltar (cuyos habitantes votaron por el
Remain y en contra del Brexit) y España, en el que se han tenido que alcanzar fórmulas provisionales para que España y Frontex custodien la frontera exterior de la UE frente al Peñón sin menoscabar las posibilidades de trabajo de los habitantes del Campo de Gibraltar que cada día acuden a la colonia británica.

España ha vivido en 2021 un cierto idilio con la Unión Europea como consecuencia de la apertura a España de los primeros fondos provenientes del Next Generation EU, y con la confianza de que los créditos y subvenciones de tales fondos europeos ayudarán a transformar la economía española en sectores tan importantes como el de las energías limpias, la digitalización y el medioambiente, para lo cual España aprobó su Plan de Recuperación, Transformación y Resiliencia (11 de mayo), y pudo discutirlo en el diálogo mantenido por el presidente Pedro Sánchez con la presidenta de la Comisión Europea, Ursula von der Leyen, en su visita a España (16 de junio), y con la participación de la vicepresidenta Calviño en reuniones del ECOFIN, así como los contactos con la presidenta del BCE Christine Lagarde y su vicepresidente Luis de Guindos, y con el Gobernador del Banco de España Pablo Hernández de Cos, que es, asimismo, presidente del Comité de Supervisión Bancaria de Basilea desde 2019.

El 11 de mayo de 2021, el Consejo de Ministros aprobó el Plan de Acción para la Internacionalización de la Economía Española 2021-2022, elaborado por la Secretaría de Estado de Comercio del Ministerio de Industria, Comercio y Turismo en colaboración con sus organismos e instrumentos dependientes (ICEX, CESCE, COFIDES, FIEM y FIEX/FONPYME) y otros ministerios, consultadas las comunidades autónomas y el sector privado. Plan elaborado con la idea de que la internacionalización ayude a $\triangleright$ 
la recuperación pospandémica con exportaciones, atracción de inversiones extranjeras, innovación, desarrollo de talento y mejor coordinación.

Los precios agrícolas han subido para los consumidores (pero con escaso aumento para los productores), y también los de la energía y los carburantes, que se han disparado a lo largo de 2021, lo cual repercute en los costes del transporte, el presupuesto de las familias y los costes empresariales. El alto precio del gas importado y los escasos avances en las energías alternativas, consecuencia de la reticencia de los grupos ecologistas respecto a la creación de parques eólicos y el poco peso de la energía atómica por la campaña en contra que se produjo hace unos años, ayudan al poco desarrollo de las fuentes energéticas capaces de producir electricidad y porque, además, España está relativamente poco conectada con las redes energéticas europeas, cosa que deberá corregirse con la Global Gateway, anunciada el 15 de septiembre (una nueva estrategia europea para impulsar vínculos inteligentes, limpios y seguros en los sectores digital, energético y del transporte). Todo ello va a hacer difícil que el sector automovilístico español pueda apostar decididamente por que los consumidores opten por el coche eléctrico, a pesar de que varias de las factorías de coches de multinacionales en España han empezado o van a empezar en breve la producción de tales vehículos.

Las tensiones entre Argelia y Marruecos con el corte del suministro del gaseoducto que transita por Marruecos no va a facilitar las cosas pese a las garantías dadas a España por el Gobierno argelino de alimentar más el gaseoducto directo (MEDGAZ) desde Hassi R'mel hasta Almería. Solamente la llegada de gas norteamericano a España, asociado a un clima menos frío y a las vacaciones navideñas a finales de diciembre, ha hecho bajar el coste de la energía eléctrica desde 400 a menos de 100 euros/MWh. que luego ha tenido un rebote. Estos precios son muy superiores a los que se contabilizaban en enero de 2021, que estaban en torno a los 40 euros/MWh.

En relación con la cooperación al desarrollo, han seguido las penurias de la Agencia Española de Cooperación al Desarrollo, pese a los propósitos al respecto que se debatieron en la VI Reunión de embajadores españoles en el extranjero, que se volvió a realizar tras doce años de no celebrarse (18-19 de enero). Empezada la vacunación anticovid a principios de enero de 2021, la cooperación española ha avanzado en la cesión de vacunas a los países en desarrollo a través del programa COVAX, lo cual va a verse reforzado por el hecho de que el Banco Europeo de Inversiones ha concedido un crédito a la empresa catalana HIPRA para empezar la producción en masa de vacunas anticovid en España.

Se está a la espera de la nueva ley de cooperación al desarrollo pese a que en la reunión de los embajadores españoles en el extranjero se comentó que estaba muy avanzada su elaboración, si bien, de momento, en el mes de julio, se aprobó la Estrategia de Respuesta Conjunta de la Cooperación Española a la Crisis del COVID-19, planteada entre la Administración General del Estado, las comunidades autónomas y las entidades locales y la Confederación de Fondos de Cooperación y Solidaridad, así como ONG y expertos, para ser presentada a la Comisión Interterritorial de Cooperación y la Comisión Interministerial con objeto de acelerar las transformaciones necesarias para coadyuvar a que los países en desarrollo puedan alcanzar los objetivos de la Agenda 2030 bajo el liderazgo de las Naciones Unidas. 


\section{Bibliografía}

Aghion, P., Antonin, C., \& Bunel, S. (2021). The Power of Creative Destruction. Harvard University Press.

Aldecoa, F. (Ed.) (2021). El Movimiento Europeo. Lugar de encuentro entre los españoles 19492021. Catarata.

Arnal, J., Díez Gibson, J. L., Muñoz Moldes, J., y Menéndez-Morán Pazos, M. E. (2021). AMCESFI. La política macroprudencial en España y en el marco internacional. Información Comercial Española, Revista de Economía, (918), 9-23. https://doi.org/10.32796/ice.2021.918.7153

Attali, J. (2021). La Economía de la vida: prepararse para lo que viene. Libros del Zorzal.

Barbé, E. (Dir.) (2021). Las normas internacionales ante la crisis del orden liberal. Tecnos.

Barnier, M. (2021). La Grande Illusion. Journal secret du Brexit 2016-2021. Gallimart.

Becker J. (2021). Made in China. Wuhan, Covid and the Quest for Biotech Supremacy. Hurst Company.

Borrell, J. (2021). European Foreign Policy in Times of Covid. European Union, External Action Service. https://eeas.europa.eu/sites/default/files/ eeas_2020.6338_european_foreign_policy_in_ times_of_covid19_web_new.pdf

Burgis, T. (2020). Kleptopia: How Dirty Money is Conquering the World. William Collins.

Colomer, J. M., y Beale, A. L. (2021). Democracia y Globalización. Ira, miedo y esperanza. Anagrama.

De Sousa Santos, B. (2021). El futuro comienza ahora: de la pandemia a la utopía. Akal.

Fusaro, D. (2021). Historia y conciencia del precariado: siervos y señores de la globalización. Alianza Editorial.

Gates, B. (2021). Cómo evitar el desastre climático. Las soluciones que ya tenemos y los avances que aún necesitamos. Plaza y Janés.
Granell, F. (2021). El Post Brexit. Món Jurídic, (233), 62-64.

Keen, S. (2021). ¿Podemos evitar otra crisis financiera? Capitán Swing.

Kelton, S. (2021). El mito del déficit: la teoría monetaria moderna y el nacimiento de la economía de la gente. Taurus.

Lamo de Espinosa, E. (2021). Entre águilas y dragones. El declive de Occidente. Espasa.

Leibbrandt, G., \& Teran, N. de. (2021). The Pay off: How Change the Way we Pay Changes Everything. Elliot and Thompson.

Lonergan, E., y Blyth, M. (2021). Angrynomics. La Economía y el descontento social actual. EDAF.

López-Aranguren, E. (2021). El populismo y la ideología populista. Editorial Popular.

Malamud, C. (2021). El sueño de Bolivar y la manipulación bolivariana. Falsificación de la historia e integración regional en América Latina. Alianza Editorial.

Mazzucato, M. (2021). Misión económica: una guía para cambiar el capitalismo. Taurus.

Moreno García-Cano, L. Ó. (2021). La geopolítica del gas: el Magreb y el suministro energético en España. Boletín Económico de Información Comercial Española, (3141), 39-55. https://doi. org/10.32796/bice.2021.3141.7318

Mosquera Valderrama, I. J., Lesage, D., \& Lips, W. (Eds.) (2021). Taxation, International Cooperation and the 2030 Sustainable Development Agenda. Springer. https://doi. org/10.1007/978-3-030-64857-2

Mulet, J. M. (2021). Ecologismo real. Destino.

Niblett, R. (2021). Global Britain, global broker. Chatan House. https://www.chathamhouse.org/sites/ default/files/2021-02/2021-01-11-global-britainglobal-broker-niblett.pdf

Norberg, J. (2021). Abierto: historia del progreso humano. Deusto. 
Onrubia, J., y Sánchez Fuentes, J. A. (Coord.) (2021). La fiscalidad internacional ante los retos de la globalización, la digitalización y el envejecimiento. Revista de Economía, Información Comercial Española, (917).

Piketti, T. (2021). Une brève histoire de l'égalité. Seuil.

Prestowitz, C. (2021). The World turning Upside Down. America, China and the Struggle for Global Leadership. Yale University Press.

Randow, J., y Speziale, A. (2021). Mario Draghi, el artífice: la verdadera historia del hombre que salvó el euro. Deusto.

Rifkin, J. (2021). El Green New Deal Global. Por qué la civilización de los combustibles fósiles colapsará en torno a 2028 y el audaz plan económico para salvar la vida en la Tierra. Booket.

Rodríguez Braun, C., Blanco, M., y Ávila, L. D. (2021). Hacienda somos todos, cariño. Cómo nos engañan para que creamos que pagamos poco $y$ por nuestro bien. Deusto.

Sachs, J. D. (2021). Las edades de la globalización. Geografía, tecnología e instituciones. Deusto.

Saez, E., y Zucman, G. (2021). El triunfo de la injusticia. Cómo los ricos eluden impuestos y cómo hacerles pagar. Taurus.

Sánchez de la Cruz, D. (2021). Liberalismo a la madrileña. Cómo y por qué Madrid se ha convertido en la comunidad que más crece, más empleo genera, mejores servicios públicos ofrece, más recauda y más baja los impuestos. Deusto.

Sanz, A. (Coord.) (2021). Una política comercial para el mundo de hoy. Revista de Economía, Información Comercial Española, (922).

Scott, L. (2021). La economía doble X. El extraordinario potencial de contar con las mujeres. Temas de Hoy.

Sebastián, C. (2021). El capitalismo del siglo XXI. Mayor desigualdad, menor dinamismo. Galaxia Gutenberg.
Subdirección General de Estrategia de Internacionalización. (2021). El Plan de Acción para la Internacionalización de la Economía española 2021-2022. Boletín Económico de Información Comercial Española, (3138), 17-32.

Subdirección General de Estudios y Evaluación de Instrumentos de Política Comercial. (2021). Recuperación económica y problemas de abastecimiento: el papel de los fletes. Boletín Económico de Información Comercial Española, (3141), 3-23.

Shafik, M. (April 2021). What we owe each other. A new social contract for a better society. Finance \& Development. International Monetary Fund.

Shiller, R. (2020). Narrativas económicas. Cómo las fake news y las historias virales afectan la marcha de la economía. Deusto.

Stephens, P. (2021). Britain alone. The Path from Suez to Brexit. Faber.

Stiglitz, J. (2021). Reescribir las reglas de la economía europea. Propuestas para el crecimiento y la prosperidad compartida. Antoni Bosch.

Taibo, C. (2021). Iberia vaciada: despoblación, decrecimiento, colapso. Catarata.

Tamames, R. (2021). Mas allá de la maldita pandemia. El informe Tamames para la recuperación económica de España. Erasmus Ediciones.

Tooze, A. (2021). El apagón. Cómo el coronavirus sacudió la economía mudial. Crítica.

Torres, J. (2021). Econofakes. Las 10 grandes mentiras económicas de nuestro tiempo y cómo condicionan nuestra vida. Deusto.

Turpyn, V. (2021). La collapsologie heureuse. L'art de se préparer au changement! Rustica Éditions.

Varoufakis, Y. (2021). Otra realidad. ¿Cómo sería un mundo justo y una sociedad igualitaria? Deusto.

Vela, C. (2021). Capitalismo patológico. Kaxilda.

Villar, H. (2021). Esclavos Unidos. La otra cara del American Dream. Akal. 